\title{
Ortopedi ve travmatolojide alçı
}

\section{Plaster in orthopaedics and traumatology}

\author{
Bülent Dağlar
}

Özel Ankara Güven Hastanesi, Ortopedi ve Travmatoloji Kliniği, Ankara

\begin{abstract}
Kırık ve çıkıklarla iskelet sisteminin birçok yaralanmasında alçı çok eskiden beri kullanılmaktadır. Alçıdan önce kullanılan sabitleme yöntemlerinin birçok dezavantajı alçı sargılarla giderilmiştir. Etkilenen bölgenin hareketsizleştirilmesi ve varsa kırıkların sabitlenmesinde halen en çok kullanılan konservatif tedavi yöntemi, alçı sargılarla yapılan çevresel alçılar ve değişik atellerdir. Ortopedi ve travmatoloji uzmanlık eğitimi ve sonrasında her uygulamayla edinilen tecrübeler ile, her hekim bu sanatı öğrenir ve geliştirir. Bu makalenin amacı, sık kullandığımız alçı sargıların tarihsel gelişimi ve çok bahsedilmeyen yapısal özelliklerinin derlenmesidir.
\end{abstract}

Anahtar sözcükler: alçı, alçılama, atel, konservatif tedavi
The plaster has been used for a very long time in the treatment of injuries in the skeletal system including fractures and dislocations. Many disadvantages of the previously used methods were overcome using gypsum. The most commonly used conservative treatment method for the immobilization of the affected area and for the stabilization of fractures is still circumferential plaster casts and various splints made of gypsum. With the expertise of orthopedics and traumatology and the experience acquired by each practice, every physician learns and develops this art. The aim of this article is to compile the historical development of the plaster casts that we use frequently, and to summarize the structural properties that we do not speak often.

Key words: plaster, cast, splint, conservative treatment
K Irık veya ortopedi denince ilk akla gelenlerden biri beyaz alçı ile kaplanmış uzuvlardır. Bu yazıyı okuyan siz meslektaşlarımızın bir bölümü, mesleğimizin önemli işaretlerinden biri olan beyaz alçıyı artık çok az kullanır hale gelmiştir. Ancak, halen kullanımı yaygın olan beyaz alçı ve alternatifleri ortopedi ve travmatolojinin vazgeçilmez gereçlerindendir. İster yaralanma nedeniyle olsun ister diğer nedenlerle, hasarlı bölgenin alçı materyali ile yapılan atel veya sirküler alçı tespitleri ile dinlenmeye alınması, olgunun rahatlatılmasındaki ilk aşamalardandır. Alçının bu tespiti yaparken kullanılma şekli, meslek yaşantısı boyunca edinilen bir sanattır. Uzmanlık eğitimimiz boyunca değerli hocalarımız ve kıdemlilerimizden görerek ve okuyarak öğrenmeye başladığımız bu sanatı her uygulamada geliştirmeye devam ederiz. Bununla birlikte, bu sanatı geliştirirken kullandığımız materyal ile ilgili pek az teorik bilgi ediniriz. Bu yazının amacı, meslek hayatımızın ayrılmaz parçası olan alçı ile ilgili pratik ve sıkıcı olmayan bilgileri derleyerek, pratik uygulamadaki sanatımızın gelişmesine katkıda bulunmaktır.
Gelin mesleğimizin belirteçlerinden biri olan beyaz alçı ile başlayalım. Doğada alçı taşı şeklinde bulunan beyaz kalsiyum sülfat, alçı olarak çok uzun zaman önce kırık tedavisinde kullanılmaya başlanmıştır. Tarihsel süreçte, kırık ve çıkıkların tedavisinde kalsiyum sülfat alçıdan önce de değişik alçı tespitleri kullanılmıştır. İsterseniz, alçıdan önce kullanılmış olan, yumuşak halde sarılan ve sonradan sertleşerek kırık tedavisinde kullanılan malzemelerden de bahsedelim. Uzuvların etrafında dönen sargılarla yapılan kırık tespitlerinin varlığı M.Ö. 9000'li yıllardan kalma mezarlar ve M.Ö. 3000'li yıllardan kalan papirüs kayıtlarıyla sabittir. Bu ilk kullanımlarda, uzuv birden fazla çubuk ve sargılarla tutturulmuştur. Sargının kat sayısının arttırılması şeklinde başlayan sağlamlaştırma denemeleri, bir süre sonra, sargılara uygulama sonrası kendiliğinden sertleşen reçinelerin eklenmesiyle devam etmiştir. Romalılar, uzuvları kutular içine alıp etraflarında reçine veya killi toprak dolgularla sertleştirecek uygulamalar yapmışlardır. Bu uygulamaların ortak dezavantajı, hastanın hareketlenmesine izin vermemesi ve eğer

- Illetişim adresi: Prof. Dr. Bülent Dağlar, Özel Ankara Güven Hastanesi, Şimşek Sokak, No:29, 06540, Kavaklıdere, Çankaya, Ankara Tel: 0532 - 3577733 e-posta: bulentdaglar@gmail.com

- Geliş tarihi: 1 Ağustos 2018 Kabul tarihi: 1 Ağustos 2018 
sabitlenen bölgede bir yara varsa bunun bakımını önlemesiydi. ${ }^{[1,2]}$ Kalsiyum sülfat alçı da, materyal olarak M.Ö. 5000'li yıllarda yüzey düzeltme ve dolgu olarak kullanılmaya başlanmıştır. Eski hiyerogliflerin önemli bölümünün, alçı ile kaplanarak düzeltilmiş yüzeyler üzerine yapıldığı görülmektedir. Eski Yunan'da da evlerin duvarları dayanıklı alçı malzeme ile kaplanarak sağlamlaştırılmıştır. Ortopedide kullandığımız şekline benzer sertleşen sargı ile tespit, tahmin edin ilk kim tarafından kullanılmıştır? İsterseniz, birkaç ipucu vererek hatırlamanıza yardımcı olayım: Matematik, felsefe, fizik, kimya, astronomi alanlarında bilinen birçok eseri olan, tıp alanındaki eserleri yaşadığı 10. yüzyılın çok sonrasında da takip edilen, bugün Özbekistan sınırları içinde, Buhara yakınlarındaki Afşana kentinde doğmuş bir bilim insanıdır. Bu kısa bilgi yetmediyse, ipuçlarını biraz daha arttıralım: Tıbbın kanunu olarak çevrilebilecek El-Kanun fi't-Tıb ile Kitabü'ş-Şifa önemli tıp eserleridir. Yeterince yardımcı olamadıysam, Batı dünyasının onu Avicenna olarak tanıdığını söylediğimde, muhtemelen hepimiz Ibn-i Sina diyebiliriz. Batı literatüründe de, ibn-i Sina alçıyı kırık tedavisinde sargılar ile birlikte kullanan ilk kişi olarak bildirilmektedir. İbn-i Sina, sargılarında deniz kabuklarından elde ettiği kalsiyum oksit toz ile yumurta akını birleştirerek, bandajları uzva göre şekillendirmiş ve sertleşen sargılarla kırık tedavisi yapmıştır.

1700'lerin sonlarında, savaş cerrahları Dominique Jean Larrey, Louis Seutin, Antonius Mathijsen ve Nikolai Ivanovich Pirogov, bandajı ılçı sargıların modern kırık tedavisinde kullanımı için fikirlerini uygulamaya geçirmiş ve günümüz uygulamalarına büyük katkıda bulunmuşlardır. Napolyon'un cerrahlarından olan Larrey, kolu ampüte olan bir askere alkollü kafur, kurşunlu asetat ve yumurta akına bulanmış sargılarla alçı uygulamış, üç ay sonra sargılar açıldığında yaranın iyileştiğini görerek, bunu Askeri Doktorun Hatıraları (Mémoires de Chirurgie Militaire) eserinde aktarmıştır. Larey'in bu gözlemi, 1832 yılında William Beaumont tarafından farelerin kol ve bacak ampütasyonlarına uygulanarak, deneyle de desteklenmiştir. ${ }^{[2]}$ Seutin, bu yaklaşımı sargıları yumuşak uygulayıp uzvu nişastaya batırıp bekleterek değiştirmiş ve daha erken ambulasyon ve erken hastaneden çıkış avantajlarını gözlemlemiştir. Alfred Velpeau, Seutin'in nişastası yerine dekstrin kullanarak alçının sertleşme süresini üç günden altı saate indirmiştir. Beyaz alçının Avrupa kıtasındaki kullanımı, Berlin'den Johann Friedrich Dieffenbach'ın pes ekinovarusu düzeltme ve alçı tespiti ile tedavi ettiğini yayımlamasıyla ortaya çıkar. Bu cerrahı ziyaret ederek tekniğini gören ve uygulamaya başlayan Jules Guerin, Lancet dergisinin yayını sayesinde "Paris Alçısı"nı ilk kullanan cerrah olarak kayda geçer. Bu teknikte, uygun şekle getirilen ayaklar yanlardan desteklenecek şekilde atellenip sargılanır, sargının üzerine alçı tozu dökülür ve ayak bir kalıbın içindeki suda bekletilir. 1800 'lerin başlarında Türkiye'de de görev yapan İngiliz diplomatı Eaton, kırık tedavisinde doktorların alçı tozuna bulanmış sargıları ıslatılarak uzva sardığını raporlamıştır.

Burada bir parantez daha açıp bugün de kullanılan beyaz kalsiyum sülfat alçılara neden "Paris Alçısı" dendiğinden bahsedelim. Kalsiyum sülfat alçının ateşe dayanıklı ve hijyenik bir kaplama olduğu çok öncelerden bilinmesine rağmen, 1600 'lü yıllarda Londra'daki büyük yangınlara kadar kıta Avrupası'nda kullanımı çok yaygın olmamıştır. 1666 yılında Paris'teki çok büyük yangından sonra, kral tarafından tahta duvarların tümünün alçı ile kaplanması zorunluluğu getirilmiş; verilen süre içinde bu işlemi yaptırmayanların evleri dahil tüm duvarlarının yıkılması emri verilmiştir. Paris Montmarte çevresindeki alçı madenlerine büyük bir hareketlilik getiren bu emirle, tüm Paris binaları ve duvarları alçı ile kaplanmıştır. Böylesi büyük bir kullanım sonrası Paris alçı tozunun büyük bir kaynağı olmuş ve bu maddeye de adını vermiştir.

Modern alçı sargı uygulamaları Kıta Avrupası'nda iki savaş cerrahı Belçika'lı Antonius Mathijsen ve Rus Nikolai Ivanovich Pirogov ile başlamış sayılır. Birbirlerinden bağımsız olarak her iki cerrah da, sahada yaralanan olguların tedavilerini yaparken, vücuda göre şekillenen kalsiyum sülfat toza bulanmış sargıları kullanmışlardır. Mathijsen'in "Mathijsen A. Nieve wijze van aanwending van het typsverband bej beenbrencken. Eene bijdraze tot de militaire chirurgie. The Harlem: JB vas Loghem Jr; 1852" künyeli orijinal makalesi, sonraları tekrar yayımlanarak okuyucuya ulaştırılmıştır. ${ }^{[3]}$ Mathijsen makalesinde, tarihsel olarak kullanılan kırık tedavi metodlarının bazılarını sıralayarak, her birinin dezavantajlarından bahsetmiş ve ideal kırık tedavi sargısının özelliklerini şu şekilde sıralamıştır:

a) kolay uygulanabilmeli,

b) uygulama sonrası çabuk sertleşmeli,

c) hasarlı veya kırık bölgeye ulaşmaya izin vermeli,

d) bandajın kendisi uygulandığı bölgenin şeklini alabilmeli,

e) hasarlı bölgeden gelen akıntılar bandaja zarar vermemeli ve

f) çok ağır veya çok pahalı olmamalıdır.

Aynı makalede Mahijsen, sadece alçı sargıları değil alçı ile yapılabilecek diğer tedavi yöntemlerini de açıklamış, kendi yöntemini kullanarak tedavi uygulayan cerrahları, elde ettikleri sonuçları bilinen dergilerde yayımlamaya davet etmiştir. Pirogov, St Petersburg'da cerrahi profesörü olmuş, daha sonra Rus ordusunun 
tıbbi sorumluluğundayken, Kırım savaşı ve Sivastapol kuşatması sırasında alçı bandaj ile yaptığı kırık tedavileri, atellemeleri ve tıp dünyasına kazandırdığı eter anestezisi ile birçok hayat ve uzuv kurtarmıştır.

Sonraları, alçı sargıların ortopedik durumlarda kullanımı giderek artmıştır. Özellikle I. Dünya Savaşı sırasında, az miktarda alçı tozuna bulanmış sargılar, ticari firmaların büyük miktarda üretimleriyle yoğun şekilde kullanılmıştır. Kullanımın artmasıyla, ağırlık ve su ile temasla bozulma gibi dezavantajların üstesinden gelebilmek için farklı yöntemler denenmişse de klasik kalsiyum sülfat kullanımı devam etmiştir. Kalsiyum sülfat yerine polimerler kullanımı 1970'lerde başlamıştır. Hem daha hafif hem daha radyolüsen hem de daha suya dayanıklı sargı materyalleri, $\% 45$ poliüretan ve \%55 fiberglas kullanımı ile başlamıştır. Fiber alçı sargıların, yukarıda sayılan avantajları yanında; sert olması nedeniyle uygulamada dikkatli olunmazsa artan şişlikle dolaşım sorunlarına yol açabilmesi, uygulanan bölgeye göre yeterince iyi şekillendirilememesi (molding), açılması için özel cihazlar ve dikkat gerektirmesi gibi dezavantajları vardır.

İster kalsiyum sülfat ister fiberglas olsun, alçı sargıların uygulanmasındaki kimyasal olaylar nedeniyle açı̆̆a çıkan ısıdan ve diğer ürünlerin istenmeyen etkilerinden korunmak gerekir. Isı ile başlayalım: Hepimizin ortak gözlemi ve hastaların uygulama ile ilgili fark ettikleri ilk değişiklik, erken kuruma döneminde sargının yapıldığı bölgenin ısısının artmasıdır. Madenden çıktığı taşlaşmış haliyle hemihidrat kalsiyum sülfat su ile karşılaştığında bir kimyasal olaylar zinciri başlar. "2 $\left(\mathrm{CaSO}_{4} \cdot \mathrm{H}_{2} \mathrm{O}\right)+3 \mathrm{H}_{2} \mathrm{O} \rightarrow 2\left(\mathrm{CaSO}_{4} \cdot 2 \mathrm{H}_{2} \mathrm{O}\right)+$ ISI" şeklinde formülleştirilebilen bu kimyasal olaylar, fiber alçllar için "prepolimer $+\mathrm{H}_{2} \mathrm{O} \rightarrow \mathrm{O}_{2}+$ poliüretan polimer + ISI" şeklindedir. Prepolimer, metilen bis (4-fenil) diizosiyanat (MDI)'tır. Özellikle fiber alçı uygulanan odanın iyi havalandırılması ve personelin ıslak sargı ile doğrudan temastan kaçınması önerilir. Yapılan bir çalışmada, personelin MDI ile karşılaşma yolları olarak ortam havası, eldivenden geçiş ve cilt teması sonrası idrarda metaboliti araştırılmış, havada MDI saptanmamış, eldivenden geçmediği görülmüş̧; ancak, doğrudan cilt teması ile idrar metabolitinin saptanabildiği, fakat çalışma süresince maruz kalınan miktarın sağlığa zararlı düzeylerde olmadığı bildirilmiştir. ${ }^{[4]}$ Kalsiyum sülfat alçı reaksiyonuyla ortaya çıkan ısının $80^{\circ} C^{\prime}$ ye kadar çıkabildiği bilinmektedir. Fiber alçılarda ortaya çıkan Isı $33-39^{\circ} \mathrm{C}$ 'lerdedir. Isı ortaya çıkışını etkileyen en önemli faktörler, suyun sıcaklığı ve uygulanan kat sayısıdır. Su sıcaklığı $24^{\circ} \mathrm{C}$ 'den fazla olduğunda ve sekizden fazla kat sargı uygulandığında ısı yükselmektedir. Çocuk ve yaşlı hastalarda cildin daha hassas olduğu vurgulanarak, bu grup hastalarda su sıcaklığının oda
Isısından fazla olmaması, mümkün olan en az sargı katının kullanılması ve havalandırmanın daha rahat olabilmesi için, uygulama sonrası büyük ve yumuşak yastık desteklerin daha dikkatli kullanılması önerilmiştir. ${ }^{[5]}$

Illk üretimlerde sert olan fiber alçıların daha esnek olanları, sonradan piyasaya sürülmüş ve şişmelere karşı esneme özelliği nedeniyle tercih edilir olmuştur. Yumuşak fiber alçılarda kat sayısı ile esneklik değişmekte ve daha az esneklik istendiğinde sargı katı arttırılmaktadır. Yumuşak fiber alçı sargıları, sert sargılarla birlikte de kullanılabilmektedir.

Günümüzde, kalsiyum sülfat, sert fiber ve yumuşak fiber alçı alternatifleri ticari olarak kullanımdadır. Hangisinin en iyi olduğunu söylemek, tüm hastalar değerlendirildiğinde mümkün değildir. Her birinin avantajlı olduğu durumlar söz konusudur. Alçı sargıların uygulandıkları bölgeye göre şekillendirilebilmelerinin avantajlı olduğu durumlarda, kalsiyum sülfat alçı sargıların, daha etkili şekillendirilebilmeleri nedeniyle kullanımları avantajlıdır. Alt ekstremitede mobilizasyon ile birlikte etkili bir tespit düşünüldügüunde, daha hafif olan sert fiber alçı sargıların daha avantajı olduğu görülür. Fazla düzeltmenin gerekmediği kısa süreli tespit gereken basit kırıklarda, çocuklarda ve ileri yaş üst ekstremite olgularında, yumuşak fiber alçı sargılar avantajlı hale gelmektedir.

Mesleğimizin halen en etkili ve sık kullanılan aracı olan alçı sargılarla ilgili bilgileri kullanışlı bulacağınızı umuyor, meslek yaşantılarınızda kolaylıklar diliyorum.

\section{KAYNAKLAR}

1. Hernigou P. Plaster of Paris: the orthopaedic surgeon heritage. Int Orthop 2016;40(8):1767-79. Crossref

2. DeMaio M, McHale K, Lenhart MK, Garland J, Mcllvaine C, Rhode MG. Plaster: Our Orthopaedic Heritage: AAOS exhibit selection. J Bone Joint Surg Am 2012;94(20):e152. Crossref

3. Mathijsen A. The Classic: New Method for Application of Plaster-of-Paris Bandage. Clin Orthop Relat Res 2007;458:59-62. Crossref

4. Pearson RL, Logan PW, Kore AM, Strom CM, Brosseau LM, Kingston RL. Isocyanate Exposure Assessment Combining Industrial Hygiene Methods with Biomonitoring for End Users of Orthopedic Casting Products. Ann Occup Hyg 2013;57(6):758-65. Crossref

5. Burghardt RD, Anderson JG, Reed RA, Herzenberg JE. Exothermic properties of plaster-synthetic composite casts. J Child Orthop 2014;8(2):193-201. Crossref 